\title{
Pain Attenuation through Mindfulness is Associated with Decreased Cognitive Control and Increased Sensory Processing in the Brain
}

\author{
Tim Gard ${ }^{1,2}$, Britta K. Hölzel ${ }^{1,2}$, Alexander T. Sack ${ }^{3}$, Hannes Hempel ${ }^{2}$, Sara W. Lazar ${ }^{1}$, Dieter Vaitl ${ }^{2,4}$ and Ulrich Ott $^{2,4}$ \\ ${ }^{1}$ Department of Psychiatry, Massachusetts General Hospital, Harvard Medical School, Charlestown, MA 02129, USA, ${ }^{2}$ Bender \\ Institute of Neuroimaging, Justus Liebig University, 35394 Giessen, Germany, ${ }^{3}$ Department of Cognitive Neuroscience, Faculty of \\ Psychology and Neuroscience, Maastricht University, 6200 MD Maastricht, the Netherlands and ${ }^{4}$ Institute for Frontier Areas of \\ Psychology and Mental Health, 79098 Freiburg, Germany
}

Address correspondence to Tim Gard, Department of Psychiatry, Massachusetts General Hospital, 120 2nd Avenue, Charlestown, MA 02129, USA. Email: tgard@nmr.mgh.harvard.edu.

\begin{abstract}
Pain can be modulated by several cognitive techniques, typically involving increased cognitive control and decreased sensory processing. Recently, it has been demonstrated that pain can also be attenuated by mindfulness. Here, we investigate the underlying brain mechanisms by which the state of mindfulness reduces pain. Mindfulness practitioners and controls received unpleasant electric stimuli in the functional magnetic resonance imaging scanner during a mindfulness and a control condition. Mindfulness practitioners, but not controls, were able to reduce pain unpleasantness by $22 \%$ and anticipatory anxiety by $29 \%$ during a mindful state. In the brain, this reduction was associated with decreased activation in the lateral prefrontal cortex and increased activation in the right posterior insula during stimulation and increased rostral anterior cingulate cortex activation during the anticipation of pain. These findings reveal a unique mechanism of pain modulation, comprising increased sensory processing and decreased cognitive control, and are in sharp contrast to established pain modulation mechanisms.
\end{abstract}

Keywords: lateral prefrontal cortex, meditation, pain modulation, posterior insula, rostral anterior cingulate cortex

\section{Introduction}

Pain is a common symptom of many medical conditions and can significantly interfere with a person's quality of life and general functioning. Pain conditions show high prevalence rates and place a high burden on society with annual costs of up to $\$ 61.2$ billion (due to lost productive time) in the US alone (Stewart et al. 2003). Over the past decades, a large body of research has focused on pharmacological and nonpharmacological ways to alleviate chronic and acute pain.

Several nonpharmacological strategies can be used to modulate the experience of pain, including: distraction (Petrovic et al. 2000; Bantick et al. 2002), perceived control/ reappraisal (Wiech et al. 2006), changing expectations about the intensity of pain (Koyama et al. 2005), placebo (Wager et al. 2004; Lu et al. 2010), hypnosis (Vanhaudenhuyse et al. 2009), hypnotic suggestion (Rainville et al. 1997), nonhypnotic suggestion (Derbyshire et al. 2009), induced emotion (Roy et al. 2009), and religious contemplation (Wiech, Farias, et al. 2008). These strategies have variable effects, either reducing or not modulating activity in affective pain-related regions such as the dorsal anterior cingulate, and sensory pain-related areas such as the somatosensory cortex, the thalamus, and in some cases the posterior insula (e.g., Lu et al. 2010). Although there is no consensus, many authors also regard the posterior insula as a region related to sensory aspects of pain (Apkarian et al.
2005; Kross et al. 2011). Modulation of pain through distraction, reappraisal, and placebo often also leads to increased activation in the rostral anterior cingulate cortex (rACC), which may reflect the top-down modulation of painrelated areas. This top-down modulation is thought to be initiated by increased activity in the lateral prefrontal cortex (IPFC; Wiech et al. 2006; Petrovic et al. 2010; Wager et al. 2011). Similarly, these modulatory regions are also involved in emotion regulation (Ochsner and Gross 2005), suggesting shared mechanisms of emotion and pain modulation (Wiech, Ploner, et al. 2008).

Mindfulness has recently been described as another strategy that can effectively modulate clinical (Kabat-Zinn et al. 1985; Grossman et al. 2007) and experimentally induced pain (Kingston et al. 2007; Grant and Rainville 2009; Perlman et al. 2010; Zeidan et al. 2010, 2011). It is important to understand the mechanisms of mindfulness as a pain modulation strategy, as it is both efficacious and increasingly being applied in clinical contexts. The aim of the present study therefore is to investigate the neural mechanisms underlying mindfulnessinduced pain attenuation.

Mindfulness is a practice that has its roots in Buddhist meditation and is defined as purposefully paying attention to experiences in the present moment in a nonjudgmental way (Kabat-Zinn 1990; Grossman et al. 2004). There is growing evidence that mindfulness-based interventions are effective in treating a variety of conditions with affective components, such as anxiety and depression (Baer 2003; Hofmann et al. 2010). This is thought to be the result of improved emotion regulation through mindfulness, which involves prefrontal regions (Creswell et al. 2007; Lutz et al. 2008). Indeed, a number of studies found increased activation in PFC during the state of mindfulness (Brefczynski-Lewis et al. 2007; Hölzel et al. 2007) and during rest after a mindfulness intervention (Tang et al. 2009). Based on the suggestion that mindfulness involves prefrontal mechanisms of known emotion regulation strategies and based on the similarity between emotion regulation and pain modulation strategies, it might be hypothesized that the neural mechanisms of mindfulness-induced pain attenuation are not different from the previously mentioned mechanisms including distraction, reappraisal, and placebo.

However, the 2 key components of mindfulness, namely 1) attention to experiences in the present moment and 2) nonjudgmental attitude, are conceptually different from other attention- and cognition-driven pain modulation strategies, such as distraction, reappraisal, and change of expectations. In the strategy of distraction, attention is focused "away" from the 
pain by performing a cognitively demanding task, whereas attention is directed "toward" the pain in mindfulness (Hart 1987; Bantick et al. 2002). Although counterintuitive, some studies have shown that bringing attention toward painful stimuli, specifically to the objective/sensory aspects can result in decreased pain perception, especially in subjects with high health anxiety (Hadjistavropoulos et al. 2000) and high fear of pain (Roelofs et al. 2004). As mindfulness involves bringing the focus of attention toward the sensory aspects of pain (Hart 1987), and as it has been shown that attention toward sensory stimuli results in increased recruitment of the respective neural representation (Gregory et al. 2003), we might expect increased recruitment of sensory areas during mindfulnessinduced pain attenuation.

Reappraisal involves actively reinterpreting the pain, for example, as less threatening or relevant (Wiech et al. 2006), whereas the pain is not judged or appraised at all in mindfulness. Furthermore, mindfulness does not involve striving to change expectations about the intensity of the pain stimulus-by definition a top-down process (Koyama et al. 2005)_rather, mindfulness emphasizes bottom-up processing of sensory stimuli. Mindfulness is also different from a placebo response, which involves both a modification of the expectations about stimulus intensity and reappraisal of the stimuli (Wiech, Ploner, et al. 2008).

A recent neuroimaging study provides preliminary support for the notion that mindfulness is different from attention- and cognition-driven pain and emotion regulation strategies by showing that mindfulness practitioners have different neuronal responses to painful stimuli than controls, involving greater activation in the insula (anterior to posterior) and thalamus and decreased activation in PFC (Grant et al. 2011, but see Brown and Jones 2010). However, these studies did not investigate a state of mindfulness but rather studied a resting state in mindfulness meditators, making the assumption that repeatedly cultivating a state of mindfulness through meditation practice results in neural processing similar to that state, even during rest. These studies also did not manipulate states of mindfulness, making it impossible to establish causality. Here, we compare states of rest with states of mindfulness to investigate the neural correlates of the pain attenuating effects of the state of mindfulness.

We hypothesize that mindfulness involves neural mechanisms to modulate pain that are different from known mechanisms such as distraction, reappraisal, and placebo. More specifically, we hypothesize that modulation through mindfulness involves decreased activity in cognitive modulatory regions, such as the $\mathrm{PFC}$, and increased activation in regions involved in sensory processing of pain, such as posterior insula, somatosensory cortex, and thalamus.

\section{Materials and Methods}

\section{Participants}

Thirty-four participants were recruited: 17 mindfulness practitioners (16 right-handed as assessed with the Edinburgh Inventory of Handedness (Oldfield 1971); 13 male, $M$ age $=37.59$ years, standard deviation $[\mathrm{SD}]=7.87$ years) and 17 controls matched for age, gender, education, and handedness (16 right-handed, 13 male, $M$ age $=36.59$ years, $\mathrm{SD}=7.80$ years). Practitioners and controls did not differ in age $\left(t_{32}=0.372, P=0.712\right)$ and education $\left(\chi_{1}^{2}=1.619, P=0.203\right)$. Neither practitioners nor controls were suffering from psychological illness or were taking medication. Practitioners were all trained in Vipassana meditation, 12 in the tradition of Goenka (Hart 1987) and 5 in other Vipassana traditions, and their experience ranged from 910 to $20855 \mathrm{~h}$ $(M=5979 ; \mathrm{SD}=5114)$ and 1.93 to 24.56 years $(M=10.20 ; \mathrm{SD}=6.85)$. Controls had no prior experience with meditation. Practitioners were recruited from German meditation centers, and controls were recruited through advertisements on notice boards and online classifieds. In an attempt to recruit groups with comparable lifestyles, advertisements stated that we were looking for subjects with a healthy lifestyle. Participants received a compensation of $€ 25$ or travel reimbursement. All participants complied with scanner safety requirements and provided written informed consent after receiving written information about the study. The study was approved by the ethics committee of the Psychology Department of Giessen University.

\section{Electrical Stimulator}

Transcutaneous electrical stimuli were generated with a custom-made impulse generator ( $833 \mathrm{~Hz}$; Stark et al. 2006). Stimuli were applied to the left lower arm, using stainless steel electrodes $(\varnothing=2 \mathrm{~mm})$. Electrodes were positioned and individually adjusted such that the experienced sensation was a sharp, focused needle prick. Stimulus intensity was adjusted for each participant individually to a moderate intensity level $(M=5.65, \mathrm{SD}=1.72$ on a 10 -point scale) using the ascending method of limits, starting with a charge of $103 \mathrm{~V}$ and increasing in increments of $5 \mathrm{~V}$.

\section{Image Acquisition}

Brain images were acquired with a 1.5-T Siemens Symphony scanner with standard head coil using a $T_{2}{ }^{*}$-weighted gradient echo-planar imaging sequence with 20 transversal slices (thickness $=5 \mathrm{~mm}$; gap $=1$ $\mathrm{mm}$; descending order; time repetition $[\mathrm{TR}]=2 \mathrm{~s}$; time echo $[\mathrm{TE}]=50$ $\mathrm{ms}$; flip angle $=90^{\circ}$; field of view $=192 \times 192 \mathrm{~mm}$; matrix size $=64 \times 64$ $\mathrm{mm})$. All scans were performed at the Bender Institute of Neuroimaging in Giessen, Germany.

For the purpose of normalizing functional data, structural images were acquired using a $T_{1}$-weighted magnetization prepared rapid acquisition gradient echo (MPRAGE) sequence with parameter settings as recommended by the Alzheimer's Disease Neuroimaging Initiative (ADNI; 160 sagittal slices, slice thickness $=1.2 \mathrm{~mm}, \mathrm{TR}=3 \mathrm{~s}, \mathrm{TE}=3.61$ $\mathrm{ms}$, flip angle $=90^{\circ}$, field of view $=240 \times 240 \mathrm{~mm}$, matrix $=192 \times 192$ $\mathrm{mm}$; Jack et al. 2008).

\section{Self-Report Ratings}

Stimulus intensity, unpleasantness, and anticipatory anxiety were rated with visual rating scales with the anchors "not noticeable" versus "very strong," "not unpleasant" versus "very unpleasant," and "not anxious" versus "very anxious," respectively. The intensity and unpleasantness scales were based on the scales of Price et al. (1983), and their original instructions to explain the difference between intensity and unpleasantness were used. Scales consisted of a red bar, where the length of the bar indicated the rating. The length of the bar could be adjusted in 10 increments by pressing 2 keys of a button box. A third key needed to be pressed to confirm the rating. Visual rating scales were administered in the scanner after every stimulation phase (see Fig. 1).

Before and after the scanning participants rated their mood on 7-point Likert scales. After scanning, they also rated task difficulty and the self-perceived success with which they had performed each condition on 7-point Likert scales. Furthermore, the Freiburg Mindfulness Inventory (Walach et al. 2004) and the German version of the Fear

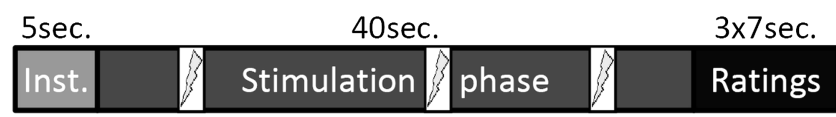

Figure 1. Stimulation protocol. Mindfulness and baseline conditions consisted of an instruction phase, a stimulation phase with 3 random shocks, and a rating phase in which intensity, unpleasantness, and anticipatory anxiety were rated on a visual rating scale. Each condition was presented 6 times, and orders were permutated within and over subjects. Inst. = instruction, sec.= seconds. 
of Pain Questionnaire (FPQ; McNeil and Rainwater 1998) were administered. During scanning, the respiration rate was recorded using the scanner's breathing belt (Siemens Symphony).

\section{Procedure}

\section{Stimulation Protocol/Conditions}

The study design was based on a mixed blocked/event-related design (Visscher et al. 2003) and employed a mindfulness condition and a baseline condition during which transcutaneous stimuli were randomly delivered to the left forearm. There also was an attention condition which will not be further discussed here as it failed to manipulate pain and anxiety perception, and there was an aversion condition which was not related to the aim of the current paper and will be reported elsewhere. Each condition was presented 6 times. Presentation of the conditions was organized into 6 blocks, such that each block comprised all conditions. After each block, there was a break ( $45 \mathrm{~s}$ ) in which participants were not stimulated. The order of conditions was permutated within and across subjects to control for carryover and sequencing effects.

During the mindfulness condition, participants (mindfulness practitioners and controls) were asked to bring their attention to the skin surface underneath the electrode on their forearm and to observe the sensations related to the stimuli, making sure to be mindful, accepting, and being aware of the transient nature of the stimuli. During the baseline condition, participants were instructed not to employ any specific strategy. During the breaks following each block, participants did not receive stimulation and were instructed to close their eyes and stay awake. Breaks comprised $5 \mathrm{~s}$ of instruction and $40 \mathrm{~s}$ of actual break with the sound of a bell at the end. Conditions were also preceded by a $5 \mathrm{~s}$ instruction with a visual presentation of the name of the condition, followed by a $40 \mathrm{~s}$ stimulation phase. During this phase, 3 transcutaneous stimuli (100 ms duration) were randomly delivered (with a minimum of $5 \mathrm{~s}$ between stimuli). As participants were asked to keep their eyes closed during all stimulation phases, the sound of a bell indicated to participants that they should open their eyes at the end of the stimulation phase and to rate intensity, unpleasantness, and anxiety on visual rating scales (duration $7 \mathrm{~s}$ each). See Figure 1 for trial structure.

\section{Instructions}

Participants received written instructions in which all conditions were described. Mindfulness instructions were based on standardized Vipassana courses as taught by Goenka (Hart 1987). To ensure that instructions were correctly understood by participants, they were asked to explain them to the experimenter. If necessary, clarification was provided. Then, participants were asked to mentally practice the different strategies. Prior to starting each test run, participants were asked to repeat the instructions once again, to make sure they remembered them in detail. In addition, after the completion of the protocol, study participants were asked to describe what they had done in each of the conditions. Reviewing the descriptions revealed that all participants had a correct understanding of the conditions.

Participants were not informed about the exact number of shocks during each condition, and no cues were presented in order to keep anticipation of shocks constant over the entire duration of each condition. Furthermore, in order to make the repeated rating of stimuli meaningful, participants were naive to the fact that stimulus intensity was kept constant.

\section{Analyses}

All analyses of behavioral data described below were conducted with SPSS 17 (SPSS Inc., Chicago, IL, USA), and all imaging data were analyzed with BrainVoyager QX 1.10.4. (Brain Innovation, Maastricht, the Netherlands).

\section{Behavioral Data}

The effects of group, time, and condition on the dependent variables intensity, unpleasantness, anxiety, and respiration rate (breaths per minute) were assessed with $2 \times 6 \times 2$ repeated measures analyses of variance (ANOVAs) with group (mindfulness practitioners vs. controls) as a between-subject factor and time (number of stimulation block 1-6) and condition (mindfulness vs. baseline) as within-subject factors. Where the sphericity assumption was not met, the Greenhouse-Geisser correction of degrees of freedom was applied. To further understand what was driving identified group $\times$ condition interactions, pairedsamples $t$-tests (two-tailed) comparing ratings during baseline and mindfulness were conducted for the mindfulness and control group separately. In addition, independent samples $t$-test (two-tailed) were conducted to test for differences in baseline ratings between mindfulness practitioners and controls. As participants did not always confirm their rating within the given time ( $7 \mathrm{~s}$ per rating), not all 36 ratings ( 2 conditions $\times 6$ repetitions $\times 3$ scales) were available for all participants. Therefore, the ANOVAs reported here are based on varying numbers of subjects. Missing values were less than $3 \%$ for most ratings, with only one rating missing $9 \%$ of values. When performing the same analyses with missing values replaced by subjects' means, comparable results to those reported here were obtained.

To rule out possible confounds, we tested for group differences in fear of pain as measured with the FPQ, chosen stimulation charge, mood, perceived task difficulty, perceived success in task performance, and respiratory rates. Between group-differences of fear of pain, stimulation charge, mood before, and mood after scanning were assessed with independent samples $t$-tests (two-tailed). To compare the difficulty and the success of adhering with the baseline and the mindfulness instructions between mindfulness practitioners and controls, 2 repeated measures ANOVAs with condition as a within-subject factor, and group as a between-subject factor were performed. To assess effects of group, condition, and time on respiration rate, an ANOVA with group, condition, and time as factors and respiration rate as dependent variable was conducted. In addition, correlations between change in respiration rate (baseline-mindfulness) and changes in stimulus intensity, unpleasantness, and anxiety (baseline-mindfulness) were calculated.

\section{Imaging}

Preprocessing. Blood oxygen level-dependent (BOLD) imaging data underwent the following preprocessing steps: 1) slice time correction with sinc interpolation, 2) 3D motion correction with trilinear/sinc interpolation, 3) drift removal consisting of linear trend removal, 4) temporal high-pass filtering at $0.0016 \mathrm{~Hz}$, and 5) spatial smoothing with an 8-mm Gaussian full-width at half-maximum kernel.

Structural brain data were resampled at $1 \times 1 \times 1 \mathrm{~mm}$ using a sinc interpolation and corrected for inhomogeneities (Vaughan et al. 2001). Subsequently, data were transformed to the anterior commissureposterior commissure (rigid body transformation) and Talairach (piecewise linear transformations) space using sinc interpolations. For the Talairach transformation, 8 landmarks were specified, dividing the brain into 12 subvolumes to which linear transformations were applied. To normalize BOLD data, functional and structural data were coregistered (header and intensity based), and the same transformation steps as performed for the structural data were applied (Goebel et al. 2006).

\section{Modeling and Statistical Tests}

One mindfulness practitioner and 2 controls were excluded from analyses because they had head motion of $3 \mathrm{~mm} /$ degrees or more (Goebel et al. 2006). Design matrices consisted of 11 predictors, namely instruction, baseline anticipation (all periods during the stimulation phase of the baseline condition except for the stimuli and the bell), baseline stimulus (i.e., electrical stimulation events during the baseline condition), mindfulness anticipation (all periods during the stimulation phase of the mindfulness condition except for the stimuli and the bell), mindfulness stimulus (i.e., electrical stimulation events during the mindfulness condition), bell, rating phase, and 2 predictors (anticipation and stimulus) for each of the other 2 conditions. To avoid overspecification, the break was not modeled. Predictors were derived by convoluting the respective boxcar waveforms with a double-gamma hemodynamic response function (onset $=0$, response undershoot ratio 
$=6$, time to response peak $=5 \mathrm{~s}$, time to undershoot peak $=15 \mathrm{~s}$, response dispersion $=1$, undershoot dispersion $=1$ ).

To investigate the neural correlates of the response to the electric stimuli without instructed regulation, whole-brain random effects (RFX) generalized linear model (GLM) analyses were performed for mindfulness practitioners and controls separately. The contrast of interest was stimulus during baseline > rest. Resulting maps were corrected for multiple comparisons using a cluster level threshold procedure that is based on the approach described by Forman et al. (1995) and has been extended and implemented in BrainVoyager QX (Goebel et al. 2006). We used this procedure with 1000 Monte Carlo simulations, a search mask excluding the skull, and a voxel level threshold of $P<0.001$. Reported clusters are significant at $P<0.05$ (extent 6 in mindfulness practitioners and 7 in controls) and were labeled using the Talairach daemon (Lancaster et al. 2000).

In order to investigate where the effect of mindfulness on brain activity during the anticipation of pain and during electric stimulation was different for mindfulness practitioners than for controls (interaction of group and condition), whole-brain RFX GLM analyses were performed. Contrasts of interests were mindfulness $>$ baseline for mindfulness practitioners $>$ controls and for controls $>$ mindfulness practitioners, and mindfulness stimulus $>$ baseline stimulus for mindfulness practitioners $>$ controls and for controls $>$ mindfulness practitioners. Resulting maps were corrected for multiple comparisons using the above outlined cluster level threshold procedure with a voxel level threshold of $P<0.05$. Reported clusters are significant at $P<0.05$ (extent 41 for the anticipation contrasts and 44 for the stimulation contrasts) and were labeled using the Talairach daemon (Lancaster et al. 2000). Post hoc analyses were conducted to further investigate what was driving the group $\times$ condition interactions in clusters in the rACC/ventromedial PFC (vmPFC), left and right IPFC, posterior insula/ S2, left temporal lobe, left superior temporal gyrus, and cerebellum, which were identified by whole-brain RFX GLM analyses. These analyses comprised paired-samples $t$-tests (two-tailed), comparing activation during mindfulness and baseline for mindfulness practitioners and controls separately, and independent samples $t$-tests (2tailed) comparing activation between mindfulness practitioners and controls during the baseline condition. Furthermore, to explore whether changes in activation in these regions were related to changes in pain reports, correlations between activations (mindfulness-baseline) in these clusters and changes in unpleasantness and anxiety ratings (baseline-mindfulness) were calculated for mindfulness practitioners and controls separately. While whole-brain analyses were corrected for multiple comparisons, post hoc analyses and behavioral analyses were not. Only significant correlations will be reported in the following section.

\section{Results}

We investigated how mindfulness modulated neural responses to pain anticipation and to pain perception. Pain was induced by transcutaneous electrical stimuli at random time intervals while participants either rested (baseline condition) or engaged in a state of mindfulness. Baseline and mindfulness conditions were each performed in six $40 \mathrm{~s}$ blocks. Subjects rated intensity and unpleasantness of the painful stimuli and anticipatory anxiety right after each block (Fig. 1). Due to missing values, analyses involving pain ratings can have a varying number of subjects. For details, see Materials and Methods.

\section{Pain Ratings}

To investigate the effects of group, condition, and time on pain intensity ratings, a repeated measures ANOVA was conducted ( $n=14$ mindfulness practitioners and 15 controls). This analysis did not reveal significant main effects for group $\left(F_{1,27}=\right.$ $2.56, P=0.617$, not significant [n.s.] $)$ or condition $\left(F_{1,27}=0.46\right.$, $P=0.502$, n.s $)$. A main effect for time was found $\left(F_{2.95,79.51}=\right.$ $\left.4.42, P=0.007, \eta_{\mathrm{p}}{ }^{2}=0.14\right)$, which can be described by a linearly decreasing function $\left(F_{1,27}=4.46, P=0.044, \eta_{\mathrm{p}}{ }^{2}=0.14\right)$, indicating habituation to the stimulus. No significant interaction effect for condition $\times$ group $\left(F_{1,27}=1.92, P=0.177\right.$, n.s. $)$ was found, indicating that the effect of condition (mindfulness vs. baseline) did not differ for mindfulness practitioners and controls (Fig. 2a). The absence of time $\times$ group $\left(F_{2.95,79.51}=\right.$ $0.16, P=0.978$, n.s. $)$ or time $\times$ condition $\left(F_{3.29,88.92}=1.32 P=\right.$ 0.274 , n.s.) interactions indicates that habituation did not differ between conditions or groups. There also was no significant 3way interaction between condition, group, and time $\left(F_{3.29,88.92}\right.$ $=0.98, P=0.411$, n.s. $)$.

A repeated measures ANOVA ( $n=14$ mindfulness practitioners and 15 controls) with group, condition, and time as factors and unpleasantness rating as dependent variable revealed a main effect for condition $\left(F_{1,27}=7.74, P=0.010\right.$, $\left.\eta_{\mathrm{p}}{ }^{2}=0.22\right)$ and time $\left(F_{5,135}=3.26, P=0.008, \eta_{\mathrm{p}}{ }^{2}=0.11\right)$, but not for group $\left(F_{1,27}=1.37, P=0.252\right.$, n.s.). This effect of time is linearly decreasing $\left(F_{1,27}=6.76, P=0.015, \eta_{\mathrm{p}}{ }^{2}=0.20\right)$, indicating that pain unpleasantness decreased over the 6 blocks. A significant interaction between group and condition was found $\left(F_{1,27}=6.11, P=0.020, \eta_{\mathrm{p}}{ }^{2}=0.19\right)$, indicating that the effect of condition (mindfulness vs. baseline) was different for mindfulness practitioners and controls (Fig. 2b). Pairedsamples $t$-tests revealed that this interaction was driven by decreased (22\%) pain unpleasantness during the mindfulness condition as compared with the baseline condition in experienced mindfulness practitioners $\left(t_{16}=2.97, P=0.009\right)$ but not in controls $\left(t_{16}=-0.13, P=0.895\right.$; Fig. $\left.2 b\right)$. Independent samples $t$-tests revealed that mindfulness practitioners and controls did not significantly differ in unpleasantness ratings during the baseline condition $\left(t_{32}=-0.23, P=0.820\right)$. The ANOVA further revealed the absence of interactions between time and group $\left(F_{5,135}=0.71, P=0.615\right.$, n.s. $)$ or time and
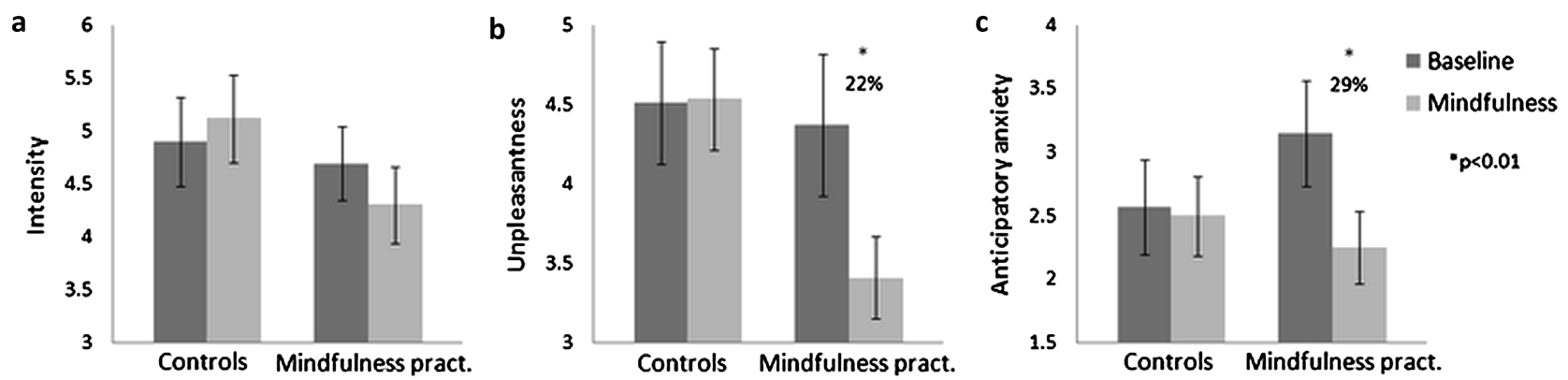

Figure 2. Pain (a) intensity, $(b)$ unpleasantness, and (c) anticipatory anxiety ratings for mindfulness practitioners (pract.) and controls in the mindfulness and baseline condition. Error bars represent standard error of the mean. 
condition $\left(F_{3.569616}=0.78, P=0.531\right.$, n.s. $)$, indicating that the habituation of the unpleasantness of the stimuli did not differ across groups or conditions. No time $\times$ group $\times$ condition interaction was found $\left(F_{3.56,96.16}=0.43, P=0.769\right.$, n.s. $)$.

Another repeated measures ANOVA was conducted to investigate the effects of group, condition, and time on anticipatory anxiety. This analysis revealed significant main effects for condition $\left(F_{1,30}=7.05, P=0.013, \eta_{\mathrm{p}}{ }^{2}=0.19\right)$ and time $\left(F_{5,150}=12.97, P=<0.001, \eta_{\mathrm{p}}{ }^{2}=0.30\right)$, but not for group $\left(F_{1,30}=0.28, P=0.601\right.$, n.s. $)$. Furthermore, a significant interaction between group and condition was found $\left(F_{1,30}=\right.$ 5.16, $\left.P=0.031, \eta_{\mathrm{p}}{ }^{2}=0.15\right)$. Paired-samples $t$-tests revealed that this interaction was driven by a significant decrease (29\%) in the mindfulness condition as compared with the baseline condition in experienced mindfulness practitioners $\left(t_{16}=2.98\right.$, $P=0.009)$ but not in controls $\left(t_{16}=0.45, P=0.659\right.$; Fig. $\left.2 c\right)$. Surprisingly, mindfulness practitioners had higher anticipatory anxiety ratings during baseline than controls $(M=3.15, \mathrm{SD}=$ 1.71 and $M=2.5, \mathrm{SD}=1.54$, respectively). However, this difference was not statistically significant $\left(t_{32}=1.036, P=\right.$ 0.308). The ANOVA further revealed the absence of time $x$ group $\left(F_{5,150}=1.10, P=0.364\right.$, n.s. $)$ and time $\times$ condition $\left(F_{3.52,105.50}=0.36, P=0.811\right.$, n.s. $)$ interactions. However, the 3 way interaction between time, group, and condition was significant $\left(F_{3.52,105.50}=2.96, P=0.029, \eta_{\mathrm{p}}{ }^{2}=0.09\right)$, can best be described as linear $\left(F_{1,30}=8.80, P=0.006, \eta_{\mathrm{p}}{ }^{2}=0.23\right)$, and is characterized by lower anxiety during mindfulness than during baseline at all time points in mindfulness practitioners and a more variable pattern of lower and higher anxiety ratings during mindfulness as compared with baseline over time in controls.

To determine whether differences in fear of pain as measured with the FPQ, chosen stimulation charge, mood, perceived task difficulty, perceived success in task performance, and respiratory rates differed between groups, thereby potentially impacting results, we tested for group differences on these variables. There were no differences in fear of pain $\left(t_{31}=1.57, P=0.126\right)$, stimulus charge $\left(t_{32}=0.63, P=0.53\right)$, mood before $\left(t_{32}=-1.2, P=0.24\right)$, and mood after $\left(t_{32}=1.53\right.$, $P=0.14)$ scanning between mindfulness practitioners and controls, indicating that these variables were not potential confounders in the current study. Furthermore, a repeated measures ANOVA with group and condition as factors and perceived difficulty of establishing the condition state as dependent variable revealed a main effect for condition $\left(F_{1,32}\right.$ $\left.=5.34, P=0.027, \eta_{\mathrm{p}}{ }^{2}=0.14\right)$ but not for group $\left(F_{1,32}=1.50, P=\right.$ 0.230 , n.s.), indicating that it was more difficult to establish the mindful state $(M=2.26 ; \mathrm{SD}=1.44$ on a 7 -point scale, collapsed over group) than the baseline state $(M=1.71$; $\mathrm{SD}=0.76)$. The absence of an interaction between group and condition $\left(F_{1,32}=\right.$ $0.37, P=0.547$, n.s.) indicates that the condition effect was not different for mindfulness practitioners and controls. An identical ANOVA with perceived success in establishing the condition state did not reveal significant effects for group $\left(F_{1,32}\right.$ $=0.19, P=0.664$, n.s. $)$, condition $\left(F_{1,32}=2.66, P=0.113\right.$, n.s. $)$, or group $\times$ condition $\left(F_{1,32}=0.14, P=0.709\right.$, n.s. $)$. This, in combination with the high average success rating $(M=5.48$; SD $=1.35$ on a 7 -point scale, collapsed over group and condition), indicates that participants, regardless of which group they belonged to, felt highly successful about establishing, maintaining, and switching between the mindfulness and the baseline states. Another repeated measures ANOVA was used to calculate the effects of group, condition, and time on respiration rate. No differences in respiratory rate were found between groups $\left(F_{1,28}=2.38, P=0.134\right.$, n.s. $)$ and conditions $\left(F_{1,28}=1.27, P=0.269\right.$, n.s. $)$, and there was no interaction between the $2\left(F_{1,28}=0.051, P=0.823\right.$, n.s. $)$. Respiratory rate also did not change over time, as indicated by the absence of a main effect of time $\left(F_{2.83,79.11}=0.53, P=0.653\right.$, n.s. $)$ or interactions between time and group $\left(F_{2.83,79.11}=1.85, P=\right.$ 0.148 , n.s. $)$, time and condition $\left(F_{5,140}=0.79, P=0.557\right.$, n.s. $)$, and time $\times$ group $\times$ condition $\left(F_{5,140}=1.01, P=0.416\right.$, n.s. $)$. There was no correlation between change (baseline-mindfulness) in respiratory rate and change (baseline-mindfulness) in rated stimulus intensity $\left(r_{28}=0.082, P=0.666\right)$, unpleasantness $\left(r_{28}=0.066, P=0.728\right)$, or anticipatory anxiety $\left(r_{28}=0.215, P=\right.$ $0.254)$, indicating that perceived pain and anxiety were not affected by respiration rate.

\section{Imaging}

\section{Pain}

As a manipulation check of the effect of the electric stimuli, we explored neural correlates of the stimuli in the baseline condition. Both mindfulness practitioners and controls showed activation in regions that are typically activated during the experience of pain, such as the ACC, insula, thalamus, S1, S2, and PFC (Fig. 3 and Tables 1 and 2).

To determine in what brain regions group $\times$ condition interaction effects on brain activity during electric stimulation occurred, a whole-brain RFX GLM analysis was performed. The contrast mindfulness > baseline for mindfulness practitioners $>$ controls revealed a significant interaction in right posterior insula extending to secondary somatosensory cortex (S2; Fig. 4 and Table 3). Post hoc paired-samples $t$-tests revealed that this interaction was driven by increased activation in mindfulness practitioners $\left(t_{15}=3.31, P=0.005\right)$ but not

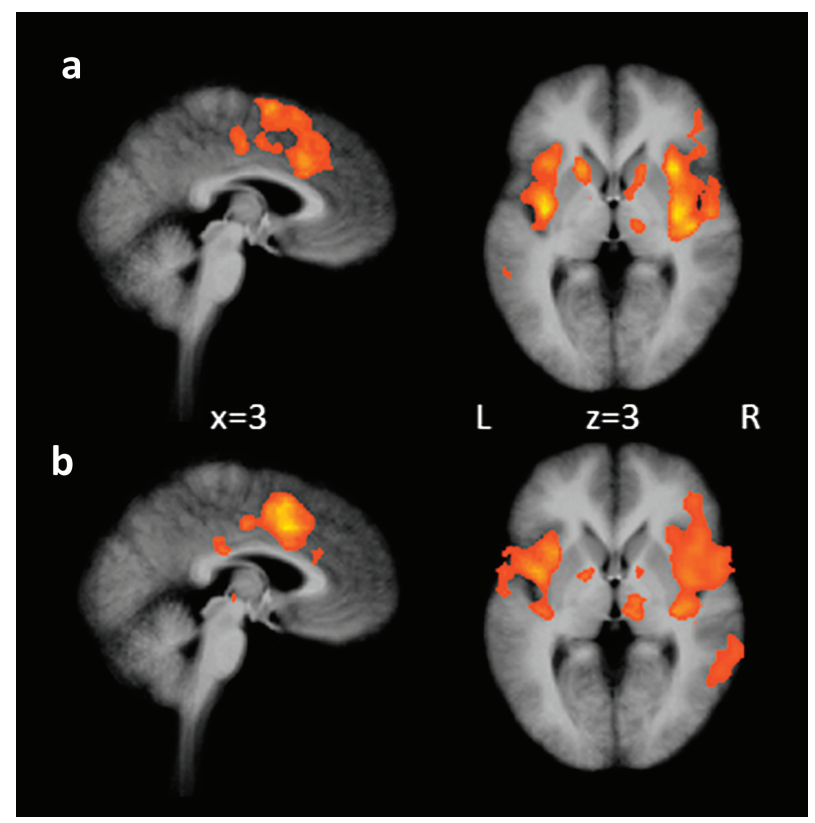

Figure 3. Activation in response to electric stimulation in (a) mindfulness practitioners and $(b)$ controls during the baseline condition. Maps are the result of a whole-brain random effects analysis and are cluster level corrected for multiple comparisons at $P<0.05$ (voxel threshold $P<0.001$, extent 6 for $a$ and 7 for $b$ ). 
Table 1

Activation in response to electric shocks in mindfulness practitioners during baseline (wholebrain corrected $P<0.05$, using cluster thresholding with voxel threshold $P<0.001$ and extent 6)

\begin{tabular}{lrlrrrrrl} 
Structure & BA & Side & $X$ & \multicolumn{1}{l}{ Y } & $Z$ & Size & $t$ & $P$ \\
\hline Insula & 13 & $\mathrm{R}$ & 42 & 2 & -8 & 33971 & 10.65 & $<0.001$ \\
S1 & 2 & $\mathrm{R}$ & & & & & & \\
S2 & 40 & $\mathrm{R}$ & & & & & & \\
IPFC & 46 & $\mathrm{R}$ & & & & & & \\
Precentral gyrus & 4 & $\mathrm{R}$ & 57 & -7 & 25 & 220 & 6.58 & $<0.001$ \\
Inferior frontal gyrus & 9 & $\mathrm{R}$ & 39 & 8 & 31 & 2502 & 8.56 & $<0.001$ \\
Thalamus & & $\mathrm{R}$ & 15 & -16 & 1 & 792 & 6.03 & $<0.001$ \\
Caudate & & $\mathrm{R}$ & 15 & 14 & 4 & 806 & 5.40 & $<0.001$ \\
Medial frontal gyrus & 6 & $\mathrm{R}$ & 3 & 2 & 61 & 8967 & 6.67 & $<0.001$ \\
& & $\mathrm{~L}$ & & & & & & \\
Cingulate gyrus & 24,32 & $\mathrm{R} / \mathrm{L}$ & & & & & & \\
Cingulate gyrus & 24 & $\mathrm{~L}$ & 0 & -16 & 37 & 821 & 5.17 & $<0.001$ \\
& & $\mathrm{R}$ & & & & & & \\
Claustrum & & $\mathrm{L}$ & -36 & -7 & 1 & 12990 & 9.72 & $<0.001$ \\
Insula & 13 & $\mathrm{~L}$ & & & & & & \\
Superior frontal gyrus & 10 & $\mathrm{~L}$ & -24 & 44 & 25 & 320 & 5.08 & $<0.001$ \\
Precentral gyrus & 9 & $\mathrm{~L}$ & -42 & 17 & 40 & 939 & 5.65 & $<0.001$ \\
Precentral gyrus & 6 & $\mathrm{~L}$ & -45 & -1 & 31 & 279 & 5.28 & $<0.001$ \\
Postcentral gyrus & 2 & $\mathrm{~L}$ & -54 & -22 & 31 & 6935 & 6.93 & $<0.001$ \\
\hline
\end{tabular}

Note: $\mathrm{S} 1$ is primary somatosensory cortex, $\mathrm{S} 2$ is secondary somatosensory cortex. Cluster size in $\mathrm{mm}^{3}$, coordinates, $t$ and $P$ values are of peak voxels, BA: Brodman area.

Table 2

Activation in response to electric shocks in controls during baseline (whole-brain corrected $P<0.05$, using cluster thresholding with voxel threshold $P<0.001$ and extent 7)

\begin{tabular}{|c|c|c|c|c|c|c|c|c|}
\hline Structure & $\mathrm{BA}$ & Side & $x$ & $Y$ & $Z$ & Size & $t$ & $P$ \\
\hline Claustrum & & $\mathrm{R}$ & 33 & -19 & 7 & 52178 & 12.46 & $<0.001$ \\
\hline Insula & 13 & $\mathrm{R}$ & & & & & & \\
\hline S1 & $1,2,3$ & $\mathrm{R}$ & & & & & & \\
\hline S2 & 40 & $\mathrm{R}$ & & & & & & \\
\hline IPFC & 10,46 & $\mathrm{R}$ & & & & & & \\
\hline Middle temporal gyrus & 21 & $\mathrm{R}$ & 51 & -28 & -8 & 208 & 4.91 & $<0.001$ \\
\hline Middle frontal gyrus & 6 & $\mathrm{R}$ & 39 & -1 & 46 & 779 & 7.18 & $<0.001$ \\
\hline Inferior parietal lobule & 40 & $\mathrm{R}$ & 39 & -46 & 37 & 1056 & 6.75 & $<0.001$ \\
\hline Postcentral gyrus & 3 & $\mathrm{R}$ & 36 & -31 & 58 & 192 & 5.86 & $<0.001$ \\
\hline Precuneus & 7 & $\mathrm{R}$ & 18 & -46 & 55 & 595 & 6.79 & $<0.001$ \\
\hline Thalamus & & $\mathrm{R}$ & 9 & -19 & 1 & 1863 & 6.42 & $<0.001$ \\
\hline Globus pallidus & & $\mathrm{R}$ & 12 & 2 & 1 & 199 & 4.97 & $<0.001$ \\
\hline Paracentral lobule & 6 & $\mathrm{R}$ & 9 & -28 & 55 & 268 & 7.36 & $<0.001$ \\
\hline \multirow[t]{3}{*}{ Cingulate gyrus } & 24 & $\mathrm{R}$ & 6 & 8 & 37 & 10751 & 8.40 & $<0.001$ \\
\hline & 24 & $\mathrm{~L}$ & & & & & & \\
\hline & 32 & $\mathrm{R} / \mathrm{L}$ & & & & & & \\
\hline Middle frontal gyrus & 6 & $\mathrm{R} / \mathrm{L}$ & & & & & & \\
\hline Cingulate gyrus & 23 & $\begin{array}{l}\mathrm{L} \\
\mathrm{R}\end{array}$ & 0 & -28 & 28 & 474 & 7.76 & $<0.001$ \\
\hline Globus pallidus & & L & -15 & -1 & 1 & 343 & 5.91 & $<0.001$ \\
\hline Insula & 13 & $\mathrm{~L}$ & -39 & -4 & -5 & 19610 & 8.55 & $<0.001$ \\
\hline S1 & 2 & $\mathrm{~L}$ & & & & & & \\
\hline S2 & 40 & $L$ & & & & & & \\
\hline Inferior parietal lobule & 40 & $L$ & -48 & -34 & 34 & 538 & 5.78 & $<0.001$ \\
\hline Inferior parietal lobule & 40 & $\mathrm{~L}$ & -45 & -46 & 40 & 320 & 5.45 & $<0.001$ \\
\hline
\end{tabular}

Note: $\mathrm{S} 1$ is primary somatosensory cortex, $\mathrm{S} 2$ is secondary somatosensory cortex. Cluster size in $\mathrm{mm}^{3}$, coordinates, $t$ and $P$ values are of peak voxels, BA: Brodman area.

in controls $\left(t_{14}=-1.80, P=0.093\right)$. There were no differences in activation during baseline between mindfulness practitioners and controls in this region $\left(t_{29}=-0.73, P=0.469\right)$. Activation (mindfulness-baseline) in this cluster was negatively correlated with a decrease in pain unpleasantness in mindfulness practitioners (baseline-mindfulness; $r_{14}=-0.529, P=0.035$ ), but was positively correlated in controls $\left(r_{13}=0.618, P=0.014\right.$; Fig. 5).

The group $\times$ condition interaction examined with the contrast mindfulness $>$ baseline for controls $>$ mindfulness practitioners further revealed significant effects in the right and left middle frontal gyrus/IPFC (Fig. 4 and Table 3). Post hoc paired-samples $t$-tests revealed that the interaction in the right IPFC was driven by decreased activation in mindfulness practitioners $\left(t_{15}=-2.25, P=0.040\right)$ and increased activation in controls $\left(t_{14}=3.87, P=0.002\right)$ in the mindfulness compared with the baseline condition. There was no difference in activation during baseline between mindfulness practitioners $\left(t_{29}=1.22, P=0.233\right)$. The interaction in the left 1 PFC was driven by a trend toward decreased activity in mindfulness practitioners $\left(t_{15}=-2.10, P=0.053\right)$ and an increase in controls $\left(t_{14}=3.19, P=0.007\right)$, and there was also no difference in baseline activity between the groups $\left(t_{29}=0.24, P=0.811\right)$. The contrast mindfulness $>$ baseline for controls $>$ mindfulness practitioners further revealed clusters in the bilateral cingulate gyrus, bilateral caudate, bilateral cerebellum, left inferior parietal lobule, and left supramarginal gyrus (Table 3).

\section{Anticipation}

Brain regions with group $\times$ condition interaction effects on brain activity during the anticipation of painful stimulation were determined with an RFX GLM. The contrast mindfulness > baseline for mindfulness practitioners > controls revealed a significant interaction in the bilateral medial frontal gyrus, specifically in the region of the rACC and the vmPFC (Fig. 4 and Table 4). The interaction in this region was driven by increased activation during mindfulness in mindfulness practitioners $\left(t_{15}=\right.$ 2.25, $P=0.040)$ and no change in controls $\left(t_{14}=-1.65\right.$, $P=0.121)$. There was no difference in activation during baseline between mindfulness practitioners and controls in this cluster $\left(t_{29}=-1.09, P=0.284\right)$. The contrast mindfulness $>$ baseline for mindfulness practitioners $>$ controls further revealed significant clusters in the left superior frontal gyrus and left superior temporal gyrus (Table 4).

In the contrast mindfulness > baseline for controls > mindfulness practitioners, significant interactions were identified in the cerebellum, left superior temporal gyrus, and left temporal lobe (Table 4 and Fig. 4). Post hoc paired-samples $t$ tests revealed that interactions in cerebellum and left superior temporal gyrus were driven by decreased activation in mindfulness practitioners during mindfulness $\left(t_{15}=-4.11, P=\right.$ 0.001 and $t_{15}=2.24, P=0.041$, respectively) and increased activation in controls $\left(t_{14}=3.28, P=0.005\right.$ and $t_{14}=2.70, P=$ 0.017 , respectively). The interaction in the left temporal lobe was driven by a tendency toward decreased activity in mindfulness practitioners $\left(t_{15}=-2.02, P=0.062\right.$, n.s. $)$ and increased activation in controls $\left(t_{14}=2.317, P=0.036\right)$. There were no differences in activation during baseline between mindfulness practitioners and controls in these regions (cerebellum $t_{29}=1.58, P=0.126$; left superior temporal gyrus $t_{29}=0.77, P=0.447$; left temporal lobe $t_{29}=1.70, P=0.099$ ). Other significant clusters in the contrast mindfulness > baseline for controls > mindfulness practitioners were found in the right superior and inferior temporal gyrus, left uncus, and in the left middle temporal gyrus (Table 4).

\section{Discussion}

The present study investigated the modulation of perceived pain and anticipatory anxiety through mindfulness in experienced mindfulness practitioners. Our finding of unchanged pain intensity and decreased (22\%) pain unpleasantness in experienced Vipassana practitioners and no changes in 


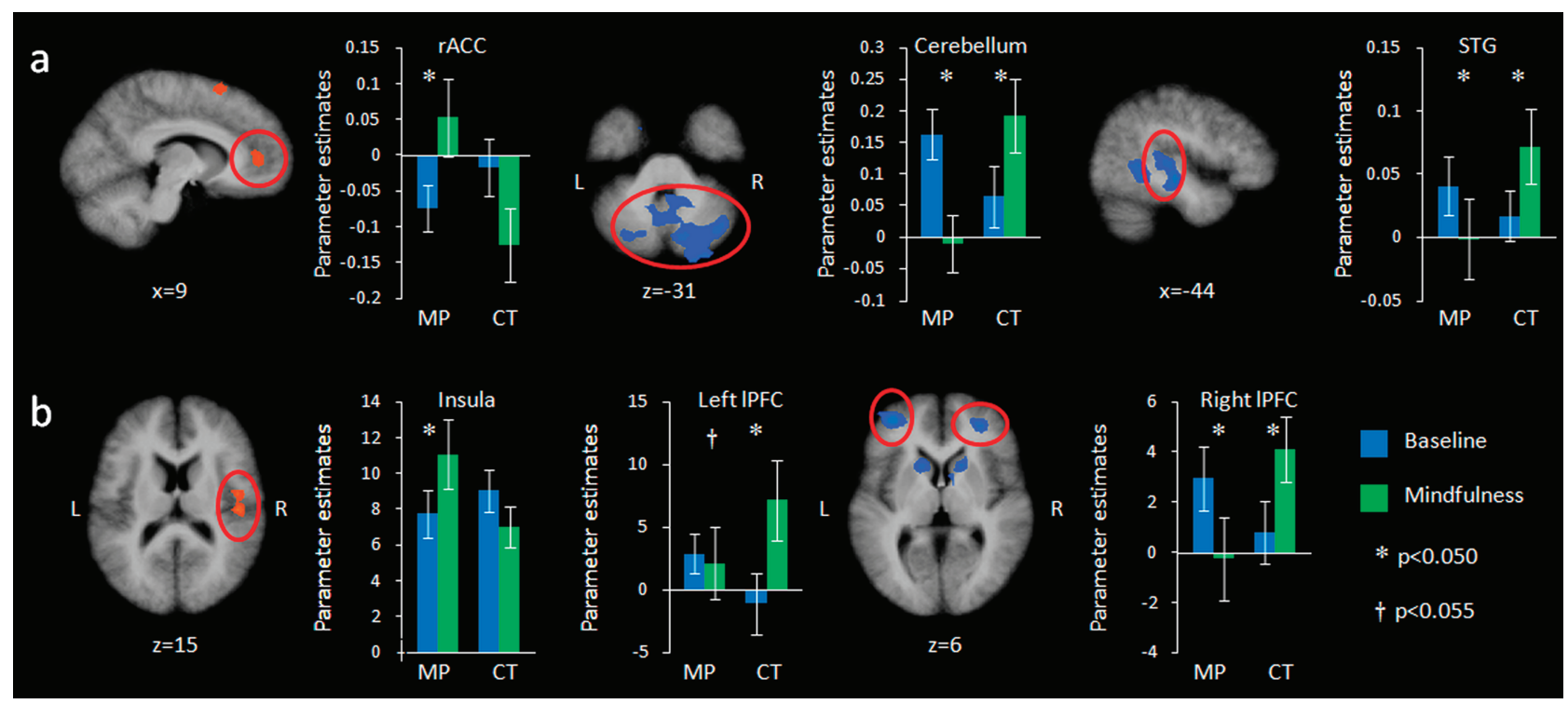

Figure 4. Activation during the baseline (blue) and mindfulness (green) condition for mindfulness practitioners (MP) and controls (CT), (a) while anticipating electric shocks and (b) while receiving electric shocks. Maps are the result of a whole-brain random effects analysis, are cluster level corrected for multiple comparisons at $P<0.05$ (voxel threshold $P<0.05$, extent 41 for stimulation and 44 for anticipation contrasts), and represent the interaction between group (mindfulness practitioners vs. controls) and condition (mindfulness vs. baseline). Red: activation greater in mindfulness practitioners; blue: activation greater in controls. Bars represent parameter estimates, error bars are standard errors of the mean. STG $=$ Superior temporal gyrus (BA22).

Table 3

Activation while receiving electric stimulation for the contrast mindfulness $>$ baseline for mindfulness practitioners $>$ controls and controls $>$ mindfulness practitioners (whole-brain corrected $P<0.05$, using cluster thresholding with voxel threshold $P<0.05$ and extent 41)

\begin{tabular}{|c|c|c|c|c|c|c|c|c|}
\hline Structure & BA & Side & $x$ & Y & Z & Size & $t$ & $P$ \\
\hline \multicolumn{9}{|l|}{ Mindfulness practitioners $>$ controls } \\
\hline Insula & 13 & $\mathrm{R}$ & 45 & -19 & 13 & 1569 & 3.59 & 0.001 \\
\hline S2 & 40 & $\mathrm{R}$ & & & & & & \\
\hline \multicolumn{9}{|l|}{ Controls $>$ mindfulness practitioners } \\
\hline Superior temporal gyrus & 39 & $\mathrm{R}$ & 42 & -49 & 28 & 1810 & 3.06 & 0.004 \\
\hline Cerebellar tonsil & & $\mathrm{R}$ & 33 & -40 & -35 & 1802 & 3.15 & 0.005 \\
\hline $\begin{array}{l}\text { Middle frontal gyrus } \\
\text { IPFC }\end{array}$ & 10 & $\mathrm{R}$ & 27 & 44 & 7 & 1515 & 4.03 & $<0.001$ \\
\hline Caudate head & & $\mathrm{R}$ & 15 & 14 & 4 & 2269 & 3.83 & $<0.001$ \\
\hline Cingulate gyrus & 1 & $\begin{array}{l}\mathrm{L} \\
\mathrm{R}\end{array}$ & -3 & -37 & 37 & 5722 & 4.35 & $<0.001$ \\
\hline Frontal & 5 & L & -3 & -40 & 55 & 3033 & 3.53 & 0.001 \\
\hline Caudate body & & $L$ & -15 & 14 & 7 & 1197 & 3.02 & 0.005 \\
\hline Cerebellum, posterior lobule & & $L$ & -36 & -67 & -38 & 2053 & 3.25 & 0.003 \\
\hline $\begin{array}{l}\text { Middle frontal gyrus } \\
\text { IPFC }\end{array}$ & 10 & $L$ & -33 & 50 & 4 & 2093 & 3.87 & $<0.001$ \\
\hline Cerebellum, culmen & & $\mathrm{L}$ & -30 & -28 & -29 & 1197 & 3.21 & 0.003 \\
\hline rietal lobule & 40 & $L$ & -30 & -31 & 37 & 1610 & 4.02 & $<0.001$ \\
\hline Supramarginal gyrus & 40 & $\mathrm{~L}$ & -51 & -40 & 31 & 7321 & 4.15 & $<0.001$ \\
\hline
\end{tabular}

Note: S2 is secondary somatosensory cortex. Cluster size in $\mathrm{mm}^{3}$, coordinates, and $t$ and $P$ values are of peak voxels, BA: Brodman area.

controls is in line with findings in experienced Zen practitioners (Grant and Rainville 2009), experienced Tibetan Buddhism practitioners (Perlman et al. 2010), and participants of a short mindfulness intervention (Zeidan et al. 2010), indicating that mindfulness, regardless of the tradition in which it is taught, has pain attenuating effects. Furthermore, our study extended these findings by investigating ratings of anticipatory anxiety. Results showed decreased anticipatory anxiety of $29 \%$ during a state of mindfulness in practitioners but not in controls. Surprisingly, mindfulness practitioners had greater but not significant $(P=0.308)$ anticipatory anxiety than controls during baseline. This might be the result of instructing mindfulness practitioners not to practice mindfulness during

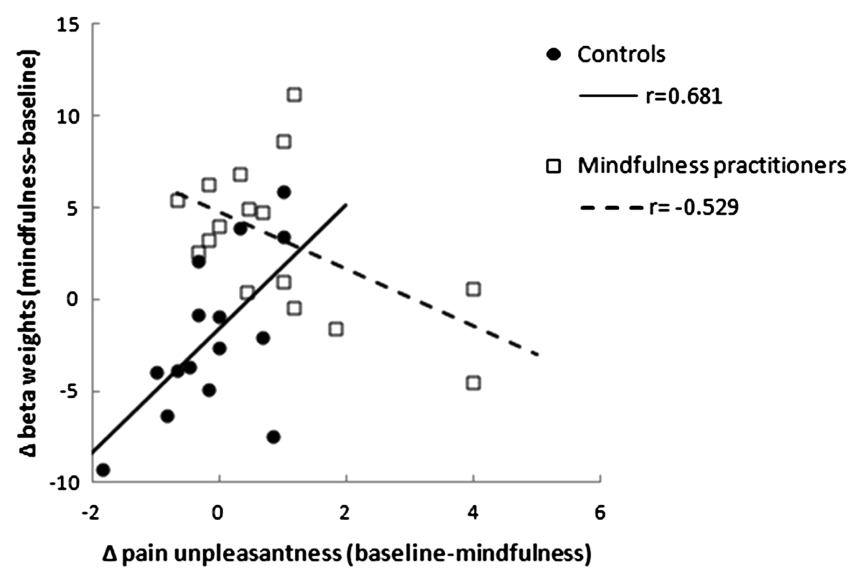

Figure 5. Correlations between reduction in pain unpleasantness during mindfulness and increased brain activity during mindfulness in posterior Insula/S2, for controls (solid line) and mindfulness practitioners (dashed line) separately.

the baseline condition, thereby preventing them to use their natural coping strategy to manage anticipatory anxiety.

This study reveals the neural mechanism by which this modulation of pain and anxiety through mindfulness is mediated. Increased activation was found in the $\mathrm{rACC} / \mathrm{vmPFC}$ in mindfulness practitioners but not in controls while anticipating pain in a state of mindfulness. When receiving the stimuli in a state of mindfulness, activation decreased in the bilateral IPFC and increased in the posterior insula/S2. This finding is striking, as the observed activation pattern is in sharp contrast to previous findings on the successful regulation of pain and anxiety (Ochsner and Gross 2005; Wiech, Ploner, et al. 2008)

Based on a literature review, Wiech, Ploner, et al. (2008) proposed a model of cognitive pain modulation according to which modulation is initiated by increased activation of the IPFC, resulting in increased activation of the periaqueductal 


\begin{tabular}{|c|c|c|c|c|c|c|c|c|}
\hline \multicolumn{9}{|c|}{$\begin{array}{l}\text { Table } 4 \\
\text { Activation during the anticipation of shock for the contrast mindfulness }>\text { baseline for } \\
\text { mindfulness practitioners }>\text { controls and controls }>\text { mindfulness practitioners (whole-brain } \\
\text { corrected } P<0.05 \text {, using cluster thresholding with voxel threshold } P<0.05 \text { and extent 44) }\end{array}$} \\
\hline Structure & BA & Side & $x$ & Y & $Z$ & Size & $t$ & $P$ \\
\hline \multicolumn{9}{|c|}{ Mindfulness practitioners $>$ controls } \\
\hline Superior frontal gyrus & 6 & $\mathrm{~L}$ & 0 & 11 & 58 & 2563 & 3.22 & 0.003 \\
\hline $\begin{array}{l}\text { Medial frontal gyrus } \\
\text { vmPFC } \\
\text { rACC }\end{array}$ & 10 & $\begin{array}{l}R \\
L \\
R\end{array}$ & 9 & 44 & 10 & 1798 & 2.8 & 0.00 \\
\hline Superior temporal gyrus & 38 & $\mathrm{~L}$ & -45 & 17 & -26 & 1947 & 3.23 & 0.00 \\
\hline \multicolumn{9}{|c|}{ Controls $>$ mindfulness practitioners } \\
\hline Superior temporal gyrus & 42 & $\mathrm{R}$ & 66 & -34 & 19 & 2112 & 3.89 & $<0.001$ \\
\hline Inferior temporal gyrus & 20 & $\mathrm{R}$ & 54 & -31 & -11 & 1222 & 2.5 & 0.00 \\
\hline Cerebellum, pyramis & & $\mathrm{R}$ & 12 & -70 & -23 & 16471 & 3.84 & $<0.001$ \\
\hline $\begin{array}{l}\text { Uncus } \\
\text { Caudate }\end{array}$ & 28 & $\begin{array}{l}L \\
L\end{array}$ & -21 & 5 & -26 & 1230 & 3.75 & $<0.001$ \\
\hline Midd & 39 & $L$ & -30 & -58 & 19 & 1547 & 3.17 & 0.00 \\
\hline Supe & 22 & $\mathrm{~L}$ & -45 & -22 & -5 & 4759 & 4.06 & $<0.00$ \\
\hline Temporal lobe & 37 & L & -45 & -46 & -5 & 1931 & 3.75 & $<0.001$ \\
\hline
\end{tabular}

Note: Cluster size in $\mathrm{mm}^{3}$, coordinates, and $t$ and $P$ values are of peak voxels, BA: Brodman area.

gray, mediated by rACC activation. This top-down modulation of pain would then result in decreased activation of brain regions involved in pain, including insula/S2 (Wiech, Ploner, et al. 2008). Although increased activation in IPFC and decreased activations in pain-related regions as proposed by this model have not been reported consistently (e.g., Bingel et al. 2006; Kong et al. 2006), increases in pain-related regions have not been reported thus far. The brain activity pattern underlying pain modulation through mindfulness as reported here is contrary to the patterns described for other known pain coping strategies.

The activation pattern of decreased IPFC activity in combination with increased posterior insula/S2 activity when receiving electric stimulation revealed in the current study is not surprising when considering the 2 conceptual components of mindfulness: 1) focusing attention on the sensory aspects of the stimulus and 2) the nonjudgmental, accepting attitude toward the experience. Based on a study showing that attention toward sensory stimuli results in increased recruitment of the respective neural representation (Gregory et al. 2003), we proposed that focusing attention on the sensory aspects of the stimulus is related to increased activation in the posterior insula, which is thought to be involved in interoceptive and sensory processing (Craig 2009). The correlation between increased insula activation during mindfulness and reduction in pain unpleasantness suggests that activation in this region is related to the pain attenuating effects of mindfulness. This relation could be explained by Leventhal's theory of dual processing, according to which individuals either process information in an objective/sensory oriented or in a subjective/emotional way (Leventhal 1982). By activating schemata of objective/sensory aspects of stimuli, instead of subjective/emotional schemata, there will be less "distress" or "suffering" during noxious stimulation (Leventhal et al. 1979). However, it remains an open question why correlations between increases in brain activation in the right posterior insula/S2 and decreases in pain unpleasantness were negatively correlated in mindfulness practitioners but positively correlated in controls.

The second component of mindfulness, the nonjudgmental and accepting attitude, could be described as cognitive disengagement, and thus an absence of cognitive control, which we hypothesize is related to the decrease in IPFC activation. That is, in contrast to other pain coping techniques, mindfulness practice is not aiming at cognitively controlling the pain but rather at "letting go" by reducing this cognitive control mechanism in the PFC of the brain. Instead, mindfulness exerts its pain and anxiety modulating effects by an increased sensory processing of the pain sensation itself and by replacing typical attempts to exert more cognitive control over the pain with a distinct brain state of cognitive disengagement and nonjudgmental sensory awareness.

The finding of a unique mindfulness brain state comprised of decreased IPFC and increased posterior insula/S2 activity is consistent with findings from a recent electroencephalography study that found decreased frontal top-down control and increased sensory processing in mindfulness practitioners when they were being presented with oddball auditory stimuli during meditation (Cahn and Polich 2009). Along the same line as our findings, a previous study showed that experienced Zen practitioners, compared with controls, had greater activation in sensory areas including posterior insula, and decreased activation in IPFC during rest when exposed to painful stimuli (Grant et al. 2011). However, this study neither manipulated nor investigated the state of mindfulness and how it modulates pain. As discussed by the authors, it is possible that effects of state mindfulness carried over into the study's rest conditions because rest and mindfulness conditions were altered in the study design. Our study explicitly investigated and manipulated the state of mindfulness, thereby allowing us to differentiate between the state of mindfulness versus the nonmeditative baseline state. It therefore reveals the neural correlates of mindfulness-induced pain attenuation.

Increased activation in the $\mathrm{rACC} / \mathrm{vmPFC}$ in experienced mindfulness practitioners while in a state of mindfulness, as we report here, has been reported previously (Brefczynski-Lewis et al. 2007; Hölzel et al. 2007). Aligned with the role of the rACC in attention regulation in affective contexts (Bush et al. 2000), it has been suggested that greater activation in this region is associated with a stronger processing of distracting events while focusing on the object of attention and maintaining a mindful state (Hölzel et al. 2007). The increased rACC/ vmPFC activation we reported during the anticipation of pain therefore might be related to the first component of mindfulness, namely focused attention.

Alternatively, our finding of increased rACC activation during the anticipation of pain might be related to the expectation of lower pain (Mobbs et al. 2007; Straube et al. 2009) or to placebo analgesia (Wager et al. 2004). However, we hypothesize that neither the mechanism of altered expectation nor that of placebo is involved in our study. Expectation and placebo analgesia involve no change or decreased activation in painrelated areas (Wager et al. 2004; Koyama et al. 2005; Petrovic et al. 2010), and placebo involves increased activation in IPFC (Wager et al. 2004; Petrovic et al. 2010), whereas we find increased activation in pain-related areas and decreased activation in IPFC.

Furthermore, activation in $\mathrm{rACC} / \mathrm{vmPFC}$ has been associated with positive emotions (Wager et al. 2008). Despite studies reporting pain attenuating effects of positive emotions (Roy et al. 2009; Villemure and Bushnell 2009), it is unlikely that our finding of decreased pain unpleasantness is due to emotioninduced pain attenuation as this involves decreased activation in sensory pain areas, whereas we found increased activation in posterior insula/S2 (Villemure and Bushnell 2009). 
In contrast to mindfulness practitioners, controls did not experience reduced pain unpleasantness or reduced anticipatory anxiety during the mindfulness condition. Congruently, no changes in activation in the rACC or posterior insula/S2 were found. The identified increase in IPFC activity in controls during mindfulness might reflect that first time practitioners engage in cognitive control while trying to be mindful. Aligned with this finding, a recent study reported that novice (4 sessions of $20 \mathrm{~min}$ ) mindfulness practitioners engaged in increased cognitive control and decreased sensory processing when down-regulating painful stimuli during a state of mindfulness (Zeidan et al. 2011). This discrepancy in modulation mechanisms between experienced mindfulness practitioners, as we report here, and novice practitioners, as reported by Zeidan et al. (2011), has recently also been reported in the context of emotion regulation (Taylor et al. 2011). Alternatively, this discrepancy in modulation mechanisms might be explained by differences in meditation practices (Cahn and Polich 2006; Lutz et al. 2007; Lutz et al. 2008; Manna et al. 2010; Travis and Shear 2010; Hölzel et al. 2011).

Like in any study involving self-report, a potential confound in the present study is self-report bias. However, the fact that changes in brain activation are in line with and in part correlated with self-reports, suggests that pain ratings are not only the result of self-report bias and have a neurobiological substrate.

In summary, our data suggest that experienced mindfulness practitioners are able to substantially decrease experienced pain unpleasantness (22\%) and anticipatory anxiety (29\%) during a mindful state. The neural correlates of this modulation involve decreased activation in the IPFC and increased activation in the posterior insula/S2 during painful stimulation, and increased rACC activation during the anticipation of pain. While the emotional aspects of the stimuli were significantly modulated by the mindful state, the pattern of brain activation is in sharp contrast to patterns typically identified in participants successfully modulating pain and anxiety. Our findings suggest that pain and anxiety modulation through mindfulness involves a unique neural mechanism in the brain, characterized by an increased sensory processing of the pain sensation itself and by replacing typical attempts to exert more cognitive control over the pain with a distinct brain state of cognitive disengagement. The identification of this distinct brain state is important as it has implications that bear on the fundamental understanding of pain and emotion regulation. Furthermore, it has clinical implications, due to its potential to empower patients with a new way of regulating pain, and make successful coping possible for those who can rely less on cognitive control. Finally, due to the high prevalence rates of pain conditions and the great burden they place on the general public (Stewart et al. 2003), our findings also have societal implications. Further exploration is vital to deepening the understanding and advancing the application of this distinct mechanism. One essential step in this direction would be to directly compare mindfulness with other pain modulation strategies.

\section{Funding}

T.G. was supported by the German Academic Exchange Service (DAAD), B.K.H. by a Marie Curie International Outgoing Fellowship within the 7 th European Community Framework
Programme, and A.T.S. by a grant from the Dutch Organization for Scientific Research (NWO; grant number 452-06-003).

\section{Notes}

We would like to thank all participants for their effort, Rainer Goebel for his help designing the study, Daniel Stölzel for help with data collection, Carlo Blecker for his help with the electric stimulator, Felix Dücker and Michelle Moerel for their help with data analysis, Armin Heinecke and Douglas Greve for consulting on analysis methods, and Narayan Brach for his help on the manuscript. Conflict of Interest: None declared.

\section{References}

Apkarian AV, Bushnell MC, Treede RD, Zubieta JK. 2005. Human brain mechanisms of pain perception and regulation in health and disease. Eur J Pain. 9:463-484.

Baer RA. 2003. Mindfulness training as a clinical intervention: a conceptual and empirical review. Clin Psychol Sci Pract. 10:125-143.

Bantick SJ, Wise RG, Ploghaus A, Clare S, Smith SM, Tracey I. 2002. Imaging how attention modulates pain in humans using functional MRI. Brain. 125:310-319.

Bingel U, Lorenz J, Schoell E, Weiller C, Buchel C. 2006. Mechanisms of placebo analgesia: rACC recruitment of a subcortical antinociceptive network. Pain. 120:8-15.

Brefczynski-Lewis JA, Lutz A, Schaefer HS, Levinson DB, Davidson RJ. 2007. Neural correlates of attentional expertise in long-term meditation practitioners. Proc Natl Acad Sci U S A. 104:11483-11488.

Brown CA, Jones AKP. 2010. Meditation experience predicts less negative appraisal of pain: electrophysiological evidence for the involvement of anticipatory neural responses. Pain. 150:428-438.

Bush G, Luu P, Posner MI. 2000. Cognitive and emotional influences in anterior cingulate cortex. Trends Cogn Sci. 4:215-222.

Cahn BR, Polich J. 2006. Meditation states and traits: EEG, ERP, and neuroimaging studies. Psychol Bull. 132:180-211.

Cahn BR, Polich J. 2009. Meditation (Vipassana) and the P3a eventrelated brain potential. Int J Psychophysiol. 72:51-60.

Craig AD. 2009. How do you feel-now? The anterior insula and human awareness. Nat Rev Neurosci. 10:59-70.

Creswell JD, Way BM, Eisenberger NI, Lieberman MD. 2007. Neural correlates of dispositional mindfulness during affect labeling. Psychosom Med. 69:560-565.

Derbyshire SWG, Whalley MG, Oakley DA. 2009. Fibromyalgia pain and its modulation by hypnotic and non-hypnotic suggestion: an fMRI analysis. Eur J Pain. 13:542-550.

Forman SD, Cohen JD, Fitzgerald M, Eddy WF, Mintun MA, Noll DC. 1995. Improved assessment of significant activation in functional magnetic resonance imaging (fMRI): use of a cluster-size threshold. Magn Reson Med. 33:636-647.

Goebel R, Esposito F, Formisano E. 2006. Analysis of functional image analysis contest (FIAC) data with brainvoyager QX: from singlesubject to cortically aligned group general linear model analysis and self-organizing group independent component analysis. Hum Brain Mapp. 27:392-401.

Grant JA, Courtemanche J, Rainville P. 2011. A non-elaborative mental stance and decoupling of executive and pain-related cortices predicts low pain sensitivity in Zen meditators. Pain. 152:150-156.

Grant JA, Rainville P. 2009. Pain sensitivity and analgesic effects of mindful states in Zen meditators: a cross-sectional study. Psychosom Med. 71:106-114.

Gregory LJ, Yaguez L, Williams SCR, Altmann C, Coen SJ, Ng V, Brammer MJ, Thompson DG, Aziz Q. 2003. Cognitive modulation of the cerebral processing of human oesophageal sensation using functional magnetic resonance imaging. Gut. 52:1671-1677.

Grossman P, Niemann L, Schmidt S, Walach H. 2004. Mindfulness-based stress reduction and health benefits - a meta-analysis. J Psychosomat Res. 57:35-43.

Grossman P, Tiefenthaler Gilmer U, Raysz A, Kesper U. 2007. Mindfulness training as an intervention for fibromyalgia: evidence 
of postintervention and 3-year follow-up benefits in well-being. Psychother Psychosom. 76:226-233.

Hadjistavropoulos HD, Hadjistavropoulos T, Quine A. 2000. Health anxiety moderates the effects of distraction versus attention to pain. Behav Res Ther. 38:425-438.

Hart W. 1987. The art of living: Vipassana-meditation as taught by S.N. Goenka. San Francisco (CA): Harper and Row.

Hofmann SG, Sawyer AT, Witt AA, Oh D. 2010. The effect of mindfulness-based therapy on anxiety and depression: a metaanalytic review. J Consult Clin Psychol. 78:169-183.

Hölzel BK, Lazar SW, Gard T, Schuman-Olivier Z, Vago DR, Ott U. 2011. How does mindfulness meditation work? Proposing mechanisms of action from a conceptual and neural perspective. Perspect Psychol Sci. 6:537-559.

Hölzel BK, Ott U, Hempel H, Hackl A, Wolf K, Stark R, Vaitl D. 2007. Differential engagement of anterior cingulate and adjacent medial frontal cortex in adept meditators and non-meditators. Neurosci Lett. 421:16-21.

Jack CR, Bernstein MA, Fox NC, Thompson P, Alexander G, Harvey D, Borowski B, Britson PJ, Whitwell JL, Ward C, et al. 2008. The Alzheimer's disease neuroimaging initiative (ADNI): MRI methods. J Magn Reson Imaging. 27:685-691.

Kabat-Zinn J. 1990. Full catastrophe living: using the wisdom of your body and your mind to face stress, pain and illness. New York: Delta.

Kabat-Zinn J, Lipworth L, Burney R. 1985. The clinical use of mindfulness meditation for the self-regulation of chronic pain. J Behav Med. 8:163-190.

Kingston J, Chadwick P, Meron D, Skinner TC. 2007. A pilot randomized control trial investigating the effect of mindfulness practice on pain tolerance, psychological well-being, and physiological activity. J Psychosomat Res. 62:297-300.

Kong J, Gollub RL, Rosman IS, Webb JM, Vangel MG, Kirsch I, Kaptchuk TJ. 2006. Brain activity associated with expectancyenhanced placebo analgesia as measured by functional magnetic resonance imaging. J Neurosci. 26:381.

Koyama T, McHaffie JG, Laurienti PJ, Coghill RC. 2005. The subjective experience of pain: where expectations become reality. Proc Natl Acad Sci U S A. 102:12950-12955.

Kross E, Berman MG, Mischel W, Smith EE, Wager TD. 2011. Social rejection shares somatosensory representations with physical pain. Proc Natl Acad Sci U S A. 108:6270-6275.

Lancaster JL, Woldorff MG, Parsons LM, Liotti M, Freitas CS, Rainey L, Kochunov PV, Nickerson D, Mikiten SA, Fox PT. 2000. Automated Talairach atlas labels for functional brain mapping. Hum Brain Mapp. 10:120-131.

Leventhal H. 1982. The integration of emotion and cognition: a view from the perceptual-motor theory of emotion. In: Clark MS, TFiske ST, editors. Affect and cognition. Hillsdale (NJ): Lawrence Erlbaum Associates, Inc. p. 121-156.

Leventhal H, Brown D, Shacham S, Engquist G. 1979. Effects of preparatory information about sensations, threat of pain, and attention on cold pressor distress. J Pers Soc Psychol. 37:688.

Lu HC, Hsieh JC, Lu CL, Niddam DM, Wu YT, Yeh TC, Cheng CM, Chang FY, Lee SD. 2010. Neuronal correlates in the modulation of placebo analgesia in experimentally-induced esophageal pain: a $3 \mathrm{~T}$ fMRI study. Pain. 148:75-83.

Lutz A, Dunne JD, Davidson RJ. 2007. Meditation and the neuroscience of consciousness: an introduction. In: Zelazo P, Moscovitch M, Thompson E, editors. The Cambridge handbook of consciousness. Cambridge (MA): Cambridge University Press. p. 499-554.

Lutz A, Slagter HA, Dunne JD, Davidson RJ. 2008. Cognitive-emotional interactions-attention regulation and monitoring in meditation. Trends Cogn Sci. 12:163-169.

Manna A, Raffone A, Perrucci MG, Nardo D, Ferretti A, Tartaro A, Londei A, Del Gratta C, Belardinelli MO, Romani GL. 2010. Neural correlates of focused attention and cognitive monitoring in meditation. Brain Res Bull. 82:46-56.

McNeil DW, Rainwater AJ. 1998. Development of the Fear of Pain Questionnaire-III. J Behav Med. 21:389-410.

Mobbs D, Petrovic P, Marchant JL, Hassabis D, Weiskopf N, Seymour B, Dolan RJ, Frith CD. 2007. When fear is near: threat imminence elicits prefrontal-periaqueductal gray shifts in humans. Science. 317:1079-1083.

Ochsner KN, Gross JJ. 2005. The cognitive control of emotion. Trends Cogn Sci. 9:242-249.

Oldfield RC. 1971. The assessment and analysis of handedness: the Edinburgh inventory. Neuropsychologia. 9:97-113.

Perlman DM, Salomons TV, Davidson RJ, Lutz A. 2010. Differential effects on pain intensity and unpleasantness of two meditation practices. Emotion. 10:65-71.

Petrovic P, Kalso E, Petersson KM, Andersson J, Fransson P, Ingvar M. 2010. A prefrontal non-opioid mechanism in placebo analgesia. Pain. 150:59-65.

Petrovic P, Petersson KM, Ghatan PH, Stone-Elander S, Ingvar M. 2000. Pain-related cerebral activation is altered by a distracting cognitive task. Pain. 85:19-30.

Price DD, McGrath PA, Rafii A, Buckingham B. 1983. The validation of visual analogue scales as ratio scale measures for chronic and experimental pain. Pain. 17:45-56.

Rainville P, Duncan GH, Price DD, Carrier B, Bushnell MC. 1997. Pain affect encoded in human anterior cingulate but not somatosensory cortex. Science. 277:968-971.

Roelofs J, Peters ML, van der Zijden M, Vlaeyen JWS. 2004. Does fear of pain moderate the effects of sensory focusing and distraction on cold pressor pain in pain-free individuals? J Pain. 5:250-256.

Roy M, Piche M, Chen JI, Peretz I, Rainville P. 2009. Cerebral and spinal modulation of pain by emotions. Proc Natl Acad Sci U S A. 106:20900-20905.

Stark R, Wolf OT, Tabbert K, Kagerer S, Zimmermann M, Kirsch P, Schienle A, Vaitl D. 2006. Influence of the stress hormone cortisol on fear conditioning in humans: evidence for sex differences in the response of the prefrontal cortex. Neuroimage. 32:1290-1298.

Stewart WF, Ricci JA, Chee E, Morganstein D, Lipton R. 2003. Lost productive time and cost due to common pain conditions in the US workforce. J Am Med Assoc. 290:2443-2454.

Straube T, Schmidt S, Weiss T, Mentzel HJ, Miltner WHR. 2009. Dynamic activation of the anterior cingulate cortex during anticipatory anxiety. Neuroimage. 44:975-981.

Tang YY, Ma YH, Fan YX, Feng HB, Wang JH, Feng SG, Lu QL, Hu B, Lin Y, Li J, et al. 2009. Central and autonomic nervous system interaction is altered by short-term meditation. Proc Natl Acad Sci U S A. 106:8865-8870.

Taylor VA, Grant J, Daneault V, Scavone G, Breton E, Roffe-Vidal S, Courtemanche J, Lavarenne AS, Beauregard M. 2011. Impact of mindfulness on the neural responses to emotional pictures in experienced and beginner meditators. Neuroimage. 57:1524-1533.

Travis F, Shear J. 2010. Focused attention, open monitoring and automatic self-transcending: categories to organize meditations from Vedic, Buddhist and Chinese traditions. Conscious Cogn. 19:1110-1118.

Vanhaudenhuyse A, Boly M, Balteau E, Schnakers C, Moonen G, Luxen A, Lamy M, Degueldre C, Brichant JF, Maquet P, et al. 2009. Pain and non-pain processing during hypnosis: a thulium-YAG event-related fMRI study. Neuroimage. 47:1047-1054.

Vaughan JT, Garwood M, Collins CM, Liu W, DelaBarre L, Adriany G, Andersen P, Merkle H, Goebel R, Smith MB, et al. 2001. 7T vs. 4T: RF power, homogeneity, and signal-to-noise comparison in head images. Magn Reson Med. 46:24-30.

Villemure C, Bushnell MC. 2009. Mood influences supraspinal pain processing separately from attention. J Neurosci. 29:705-715.

Visscher KM, Miezin FM, Kelly JE, Buckner RL, Donaldson DI, McAvoy MP, Bhalodia VM, Petersen SE. 2003. Mixed blocked/ event-related designs separate transient and sustained activity in fMRI. Neuroimage. 19:1694-1708.

Wager TD, Atlas LY, Leotti LA, Rilling JK. 2011. Predicting individual differences in placebo analgesia: contributions of brain activity during anticipation and pain experience. J Neurosci. 31:439-452.

Wager TD, Barrett LF, Bliss-Moreau E, Lindquist K, Duncan S, Kober H, Joseph J, Davidson M, Mize J. 2008. The neuroimaging of emotion. In: Lewis M, Haviland JM, editors. The handbook of emotion. 3rd ed. New York: The Guilford Press. p. 249-271. 
Wager TD, Rilling JK, Smith EE, Sokolik A, Casey KL, Davidson RJ, Kosslyn SM, Rose RM, Cohen JD. 2004. Placebo-induced changes in fMRI in the anticipation and experience of pain. Science. 303:1162-1167.

Walach H, Buchheld N, Buttenmüller V, Kleinknecht N, Schmidt S 2004. Empirische Erfassung der Achtsamkeit-Die Konstruktion des Freiburger Fragebogens zur Achtsamkeit (FFA) und weitere Validierungsstudien. In: Heidenreich T, Michalak J, editors. Achtsamkeit und Akzeptanz in der Psychotherapie. Ein Handbuch. Tübingen (Germany): dgvt-Verlag. p. 729-772.

Wiech K, Farias M, Kahane G, Shackel N, Tiede W, Tracey I. 2008. An fMRI study measuring analgesia enhanced by religion as a belief system. Pain. 139:467-476.
Wiech K, Kalisch R, Weiskopf N, Pleger B, Stephan KE, Dolan RJ. 2006. Anterolateral prefrontal cortex mediates the analgesic effect of expected and perceived control over pain. J Neurosci. 26:11501-11509.

Wiech K, Ploner M, Tracey I. 2008. Neurocognitive aspects of pain perception. Trends Cogn Sci. 12:306-313.

Zeidan F, Gordon NS, Merchant J, Goolkasian P. 2010. The effects of brief mindfulness meditation training on experimentally induced pain. J Pain. 11:199-209.

Zeidan F, Martucci KT, Kraft RA, Gordon NS, McHaffie JG, Coghill RC. 2011. Brain mechanisms supporting the modulation of pain by mindfulness meditation. J Neurosci. 31:5540. 